\title{
Population Fluctuations of Oryctes rhinoceros L. Beetle in Plant Oil Palm (Elaeis guineensis Jacq.) Given Mulching Oil Palm Empty Bunch
}

\author{
Hafiz Fauzana*1, Agus Sutikno ${ }^{1}$, Desita Salbiah ${ }^{1}$ \\ Lecturer Department of Agro Technology Faculty of Agriculture, University of Riau, Pekanbaru, Riau, Indonesia, \\ 28293 \\ *Corresponding author: fauzana_hafiz@yahoo.co.id
}

\begin{abstract}
Oil palm is a pre-eminent commodity in Indonesia, especially in Riau Province. The main pests that attack the oil palm is the pest of beetle Oryctes rhinoceros. The life cycle of pre-adult $O$. rhinoceros is on the ground, while the one that attacks the plant is the beetle stadia. The application of oil palm empty bunches (OPEB) to oil palm cultivation that functions as mulch and soil compost can improve the physical and biological properties of the soil, otherwise $O$. rhinoceros actually increases its population with OPEB application. The objective of this research is to know the population of $O$. rhinoceros in oil palm plantation given mulch of empty palm oil bunches. Research using survey method, observation done at PT. Adei Plantation \& Industry. Observations made on the pradati with the size of the soil as a sample, to catch the adult beetles used ferotrap using pheromones as much as 5 ferotrap on 10 ha of land. Observations included the pre-adult population, the beetles population of $O$. rhinoceros, sex ratio, biomass, attack intensity. The results of research that has been done shows that in the low adults population were the average of 8 tails per week, instar 2 most found was 15 tails. The population of beetles $O$. rhinoceros were the average of 23.8 tail / ferotrap / month. Population O. rhinoceros 1 st week and 2nd, 3rd week decreased, lowest was at 4th week. The sex ratio of female and male beetles was 19.4: 4.4 or 4.54: 1 . The intensity of $O$. rhinoceros attack was $11.72 \pm 2.01 \%$ belonging to the category of minor attacks.
\end{abstract}

Keywords: beetles $O$. rhinoceros, oil palm empty bunches, fluctuations, population.

\section{ABSTRAK}

Fluktuasi Populasi Oryctes rhinoceros L. Pada Tanaman Kelapa Sawit (Elaeis guineensis Jacq.) Yang Diberi Mulsa Tandan Kosong Kelapa Sawit

Kelapa sawit merupakan salah satu komoditas unggul di Indonesia, khususnya di Provinsi Riau. Hama utama yang menyerang tanaman kelapa sawit adalah kumbang Oryctes rhinoceros. Siklus hidup pra dewasa dari hama O.rhinoceros berada pada tanah, sedangkan yang menyerang tanaman berada pada stadia dewasa. Pengaplikasian tandan kosong kelapa sawit pada budidaya tanaman kelapa sawit dapat berfungsi sebagai mulsa dan kompos tanah yang dapat meningkatkan sifat fisik dan biologis tanah, selain itu populasi O.rhinoceros juga meningkat karena aplikasi tandan kosong kelapa sawit. Tujuan dari penelitian ini yaitu untuk mengetahui populasi dari O.rhinoceros pada tanaman kelapa sawit yang diberi mulsa dari tandan kosong kelapa sawit. Penelitian ini menggunakan metode survey, pengamatan dilakukan di PT. Adei Plantation \& Industry. Pengamatan dilakukan pada dengan metode mutlak dan nisbi, untuk pengambilan kumbang O. rhinoceros lokasi sampel terdiri dari 5 titik pemasangan ferotrap masing-masing titik sampel seluas 2 ha. Parameter pengamatan mencakup populasi stadia pradewasa, populasi kumbang dewasa O.rhinoceros, rasio seks, kelimpahan, dan intensitas serangan. Hasil penelitian menunjukkan bahwa populasi kumbang pradewasa terendah dengan rerata 8 ekor per minggu, instar 2 paling banyak ditemukan sebanyak 15 ekor. Populasi dari kumbang O.rhinoceros berada pada rerata 23.8 ekor/ ferotrap/ bulan. Populasi O.rhinoceros pada minggu 1, 2 dan 3 berkurang, terendah pada minggu 4. Rasio seks dari kumbang betina dan jantan yaitu 19.4: 4.4 dan 4.54: 1. Instensitas dari serangan O.rhinoceros sebesar 11,72\% tergolong ke dalam kategori serangan ringan.

Kata kunci: kumbang $O$. rhinoceros, tandan kosong kelapa sawit, fluktuasi, populasi.

\section{PENDAHULUAN}

Kumbang O. rhinoceros merupakan hama utama menyerang tanaman kelapa sawit (Elaeis guineensis Jacq.) di Indonesia. Serangan $O$. rhinoceros dapat menurunkan produksi tandan buah segar pada panen tahun pertama hingga $60 \%$ dan menimbulkan kematian tanaman muda hingga $25 \%$. Serangan kumbang $O$. rhinoceros di Provinsi Riau seluas 12.384,85 ha (Dinas Perkebunan Provinsi Riau 2014).

Pengamatan populasi yang kontinu adalah utama dalam program pengelolaan hama terpadu kumbang $O$. rhinoceros. Hasil pengamatan menentukan tindakan pengelolaan terhadap kumbang O. rhinoceros. Harahap (2010) mengatakan populasi kumbang O. rhinoceros ditemukan sebanyak 250 ekor/perangkap dengan rata-rata 33 ekor/perangkap sudah melewati batas ambang ekonomi pada tanaman kelapa sawit pada fase belum menghasilkan.

Kelimpahan populasi kumbang $O$. rhinoceros dipengaruhi oleh adanya bahan makanan yang tersedia diantaranya adalah bahan organik yang terdapat di lahan perkebunan seperti pengaplikasian mulsa tandan kosong kelapa sawit pada tanaman menghasilkan (TM) yang berlebihan dan sisa tanaman setelah replanting merupakan bahan organik yang disukai oleh kumbang O. rhinoceros (Santi dan Sumaryo, 2008).

Aplikasi tandan kosong kelapa sawit dengan dua cara yaitu pada gawang maupun pada sisi sistem 
lubang tanah besar. Pada sistem lubang tanam besar bertujuan untuk memperbaiki struktur tanah yang pada akhirnya dapat meningkatkan produktifitas kelapa sawit. Tandan kosong kelapa sawit (TKKS) diaplikasikan setelah membusuk akan menjadi tempat perkembangan $O$. rhinoceros dan dapat langsung menyerang tanaman muda hasil peremajaan (Susanto et al., 2005).

Pemberian mulsa TKKS menimbulkan kontradiksi, disatu sisi sangat menguntungkan terhadap faktor fisik, biologi, dan kandungan hara tanah, tetapi disisi lain tentunya akan mempengaruhi terhadap biologi dan kelimpahan $O$. rhinoceros di pertanaman. Sejauhmana pengaruh mulsa TKKS terhadap biologi dan kelimpahan $O$. rhinoceros di ekosistem pertanaman kelapa sawit sangat penting diteliti untuk menentukan pengelolaan yang tepat $O$. rhinoceros pada tanaman kelapa sawit.

Tujuan penelitian ini adalah untuk mengetahui fluktuasi populasi kumbang Oryctes rhinoceros L. pada tanaman kelapa sawit (Elaeis guineensis Jacq.) diberi mulsa tandan kosong kelapa sawit pada tanaman menghasilkan.

\section{BAHAN DAN METODE}

Penelitian ini dilaksanakan di kebun kelapa sawit milik PT. Adei Plantation Provinsi Riau. Agroekosistem pertanaman sampel terdapat pengaplikasian tandan kosong kelapa sawit pada lubang besar. Kumbang O. rhinoceros pradewasa dan dewasa diamati dari perkebunan kelapa sawit, simb $R b$ pheromone.

Penelitian ini menggunakan metode survei, lokasi penelitian ditentukan dengan menggunakan metode purposive sampling, tanaman sampel ditentukan secara zig zag. Jumlah sampel diambil sebanyak 5\% dari luas lahan 40 ha/blok sehingga didapat 2 ha luas sampel. Tanaman sampel yang dijadikan pengamatan sebanyak $10 \%$ dari 260 tanaman sehingga diperoleh 27 sampel tanaman.

Pengamatan $O$. rhinoceros dilakukan dengan metoda mutlak yaitu melakukan pengamatan secara langsung terhadap stadia pradewasa (telur, larva, dan pupa) dan metoda nisbi dengan menggunakan ferotrap untuk menangkap kumbang dewasa $O$. rhinoceros. Kebun yang dijadikan lokasi penelitian adalah kebun yang terdapat gejala serangan kumbang $O$. rhinoceros. Untuk pengambilan kumbang $O$. rhinoceros lokasi sampel terdiri dari 5 titik pemasangan ferotrap masing-masing titik sampel seluas 2 ha yang ditentukan secara diagonal. Ferotrap dipasang menggunakan tonggak bambu dengan ketinggian 4 meter. Pengamatan dilakukan setiap hari selama 1 bulan. Kumbang dewasa yang terperangkap diamati kumbang jantan dan betinanya berdasarkan ciri-ciri morfologi kumbang $O$. rhinoceros berdasarkan identifikasi dari Ooi, 1998. Hasil pengamatan populasi kumbang $O$. rhinoceros dianalisis statistik dengan melakukan tabulasi dan penghitungan rerata. Data disajikan dalam bentuk tabel dan grafik. Pengamatan meliputi:

\section{Populasi stadia pradewasa (telur, larva dan pupa)}

Pengamatan dilakukan di dekat perakaran tanaman kelapa sawit dengan jarak 1 meter dari pangkal kelapa sawit, dengan luas $30 \mathrm{~cm}^{2}$ dan kedalaman $30 \mathrm{~cm}$. Pengambilan dilakukan pada 4 titik tiap tanaman sampel yaitu pada posisi penjuru mata angin (sisi barat, timur, utara, dan selatan) tiap sampel tanaman kelapa sawit. Tanah digali dengan menggunakan cangkul, dimasukan ke dalam tempat ayakan, keberadaan fase pradewasa meliputi stadia telur, larva instar 1 , instar 2, instar 3, dan pupa langsung diamati dan dihitung di lapangan.

\section{Populasi kumbang dewasa $O$. rhinoceros}

Pengamatan dilakukan dengan menghitung populasi kumbang dewasa yang terperangkap dalam ferotrap diamati setiap hari jam 07.00 WIB selama satu bulan. Satu ferotrap dipasang untuk luasan 2 ha (Chung, 1997).

\section{Kelimpahan}

Analisis kelimpahan dilakukan dengan menghitung jumlah $O$. rhinoceros yang didapatkan pada 4 kali pengambilan sampel per minggu dimana kelimpahan ini dihitung berdasarkan metode penghitungan total (perhitungan menyeluruh) (Odum, 1993).

\section{Seks rasio (\%)}

Kumbang dewasa jantan dan betina dari hasil pengamatan menggunakan ferotrap dihitung perbedaan antara kumbang jantan dan betina. Seks rasio jantan dan betina dihitung dengan menggunakan rumus Suin (2002).

$$
\text { Seks Rasio }(\%)=\gg \frac{\text { jumlah kumbang jantan }}{\text { jumlah kumbang betina }} \times 100
$$

\section{Intensitas serangan}

Intensitas serangan kumbang $O$. rhinoceros pada tanaman kelapa sawit dapat dihitung dengan rumus Utomo et al. (2007) :

$$
\text { IS }=\frac{\sum(\mathrm{nxv})}{\mathrm{zxN}} \times 100 \%
$$

IS = Intensitas Serangan

$\mathrm{n}=$ Jumlah daun rusak

$\mathrm{v}=$ Nilai skala kategori serangan

$\mathrm{Z}=$ Nilai skala kategori serangan tertinggi

$\mathrm{N}=$ Jumlah daun yang diamati

\section{Kriteria serangan:}

$0=$ Tidak ada gejala serangan baru

$1=$ Serangan atau kerusakan kurang dari 5\%

$2=$ Serangan baru atau kerusakan $5-10 \%$ 
$3=$ Serangan baru dengan kerusakan tanaman 10-25\%

$4=$ Serangan baru dengan kerusakan $25-50 \%$

$5=$ Serangan berat dengan kerusakan lebih dari $50 \%$.

\section{HASIL DAN PEMBAHASAN}

\section{Populasi Stadia Pradewasa O. rhinoceros}

Hasil pengamatan yang dilakukan pada tanaman kelapa sawit. pradewasa kumbang $O$. rhinoceros yang ditemukan hanya stadia larva.
Populasi larva yang ditemukan disajikan pada Gambar 1.

Pada Gambar 1 terlihat bahwa populasi pradewasa $O$. rhinoceros pada pertanaman diberi TKKS yaitu kisaran $9-12$ ekor (total 27 tanaman sampel per minggu) atau kisaran 0,33 - 0,44 ekor per tanaman per minggu. Populasi pradewasa ini masih berada di bawah ambang ekonomi 3,8 ekor pertanaman (Samsudin et al, 1993). Populasi pradewasa $O$. rhinoceros instar 1, 2, dan 3 larva dan pupa disajikan pada Tabel 1.

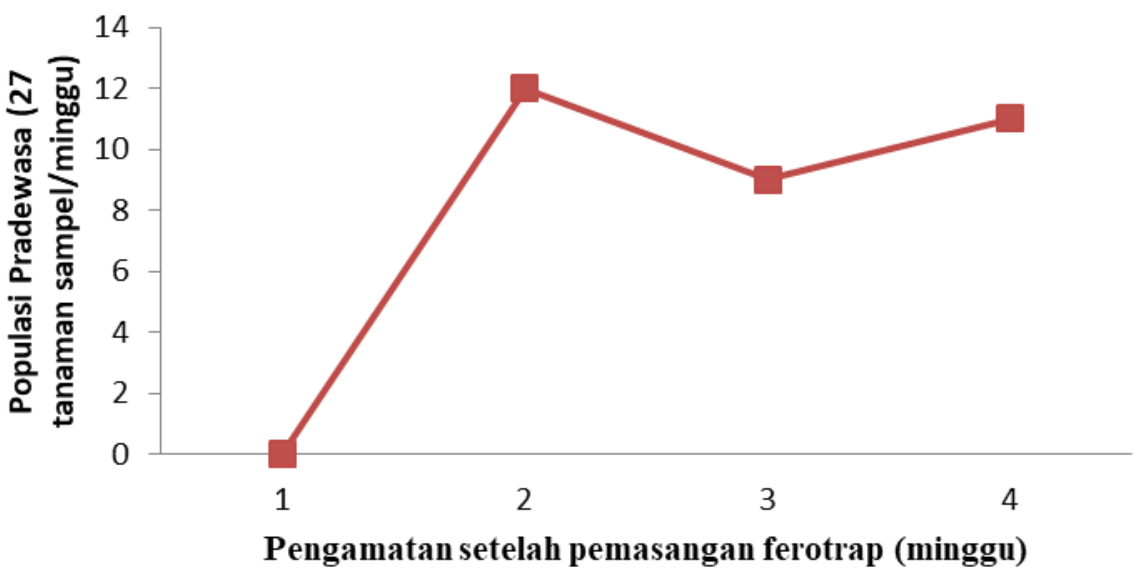

Gambar 1. Populasi pradewasa $O$. rhinoceros pada tanaman kelapa sawit

Tabel 1. Populasi instar larva dan pupa $O$. rhinoceros pada tanaman kelapa sawit

\begin{tabular}{ccccccc}
\hline \multirow{2}{*}{$\begin{array}{c}\text { Aplikasi } \\
\text { pertanaman }\end{array}$} & \multicolumn{9}{c}{ Pradewasa (Total 4 kali pengamatan \&27 tanaman } & \multirow{2}{*}{ Total } & Rerata \\
\cline { 2 - 5 } & Instar 1 & Instar 2 & Instar 3 & Pupa & & \\
\hline TKKS & 10 & 15 & 7 & 0 & 32 & 8 \\
\hline
\end{tabular}

Keterangan: TKKS (Tandan kosong kelapa sawit)

Tabel 1 menunjukkan bahwa stadia pradewasa yang dominan (total dari 4 kali pengamatan) adalah stadia larva instar 2 yaitu 15 ekor pada pertanaman. Populasi stadia pradewasa adalah total 32 ekor (Total 4 pengamatan dan 27 tanaman sampel) atau rerata 8 ekor per minggu. Aplikasi TKKS pada pertanaman kelapa sawit dapat menjadi tempat berkembangbiaknya pradewasa $O$. rhinoceros sehingga menyebabkan meningkatnya populasi kumbang O. rhinoceros. Menurut Dhileepan (1988) kumbang dapat berkembangbiak dan meletakan telur pada sisa bahan organik yang terdekomposisi seperti tumpukan TKKS.

\section{Populasi Kumbang Dewasa $O$. rhinoceros}

Hasil pengamatan pada perangkap ferotrap pada tanaman kelapa sawit terhadap populasi kumbang $O$. rhinoceros yang terperangkap pada perangkap ferotrap disajikan pada Tabel 2 dan Gambar 2.

Tabel 2 menunjukan rerata kumbang $O$. rhinoceros pada tanaman menghasilkan disetiap ferotrap yang dipasang pada perkebunan kelapa sawit pada aplikasi TKKS yaitu 23,8 ekor. Populasi kumbang per minggu disajikan pada Gambar 2.

Tabel 2. Populasi kumbang $O$. rhinoceros yang terperangkap pada ferotrap selama 1 bulan

\begin{tabular}{cccccccc}
\hline \multirow{2}{*}{$\begin{array}{c}\text { Aplikasi } \\
\text { Pertanaman }\end{array}$} & \multicolumn{5}{c}{ Populasi kumbang per ferotrap } & \multirow{2}{*}{ Total } & Rerata \\
\cline { 2 - 7 } & 1 & 2 & 3 & 4 & 5 & & \\
\hline TKKS & 16 & 12 & 27 & 17 & 47 & 119 & 23,8 \\
\hline
\end{tabular}

Dari Gambar 2 dapat dilihat bahwa jumlah populasi $O$. rhinoceros tertinggi terdapat pada minggu ke-2 setelah aplikasi, sedangkan yang terendah pada minggu ke-4. Kumbang $O$. rhinoceros tertinggi pada 
minggu ke-2 setelah aplikasi merupakan titik maksimum penyebaran feromon agregasi. Menurut Chenon dkk., (1997) menyatakan bahwa semakin tinggi temperatur maka pelepasan senyawa yang terdapat pada feromon akan semakin cepat dan lebih cepat diterima kumbang melalui penerima bau yang berada di antena (sensillum) oleh kumbang $O$. rhinoceros. Semakin lama feromon yang terpasang akan semakin berkurang kemampuan untuk menyebarkan bau.

Kecenderungan penurunan jumlah kumbang $O$. rhinoceros yang terperangkap pada minggu ke-4 disebabkan keberadaan dan penerbangan kumbang $O$. rhinoceros yang semakin berkurang karena sudah banyak terperangkap pada minggu sebelumnya. Namun demikian, menurut Price (1984) fluktuasi kumbang $O$. rhinoceros dipengaruhi oleh faktor pengendali populasi di pertanaman yaitu faktor bebas kepadatan adalah lingkungan fisik yang meliputi suhu, kelembaban, angin, curah hujan, dan lainnya. Faktor tergantung kepadatan yang mempengaruhi adalah musuh alami, makanan (TKKS) dan ruang.

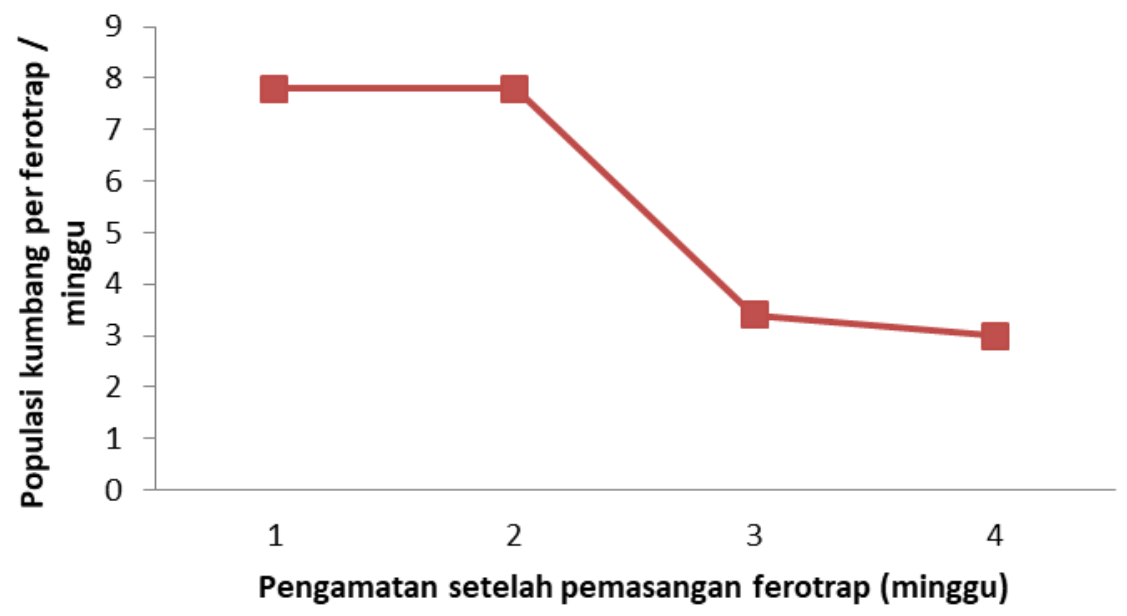

Gambar 2. Populasi kumbang $O$. rhinoceros yang terperangkap per minggu

\section{Seks Rasio Kumbang O. rhinoceros}

Berdasarkan pengamatan pada tanaman kelapa sawit menggunakan perangkap ferotrap didapat populasi kumbang $O$. rhinoceros. Hasil pengamatan populasi jantan dan betina kumbang O. rhinoceros, dan seks rasionya, disajikan pada Tabel 3.

Populasi jantan dan betina kumbang $O$. rhinoceros yang terperangkap pada perangkap ferotrap yang dipasang di lapangan lebih didominasi oleh kumbang betina. Seks rasio rerata kumbang jantan dan betina adalah 4,4:19,4 atau $1: 4,54$ (Tabel
3). Hal ini sesuai dengan hasil penelitian Allouw (2007) yang mendapatkan hasil pengamatan kumbang betina lebih banyak dari pada kumbang jantan dengan perbandingan $1,34: 1$.

Tingginya seks rasio kumbang betina dari jantan pada diberi TKKS yaitu 19,4 : 4,4 atau 4,54 : 1, ini disebabkan pada pemberian TKKS sehingga kumbang betina lebih banyak pada pertanaman untuk meletakkan telurnya. Populasi jantan dan betina kumbang $O$. rhinoceros per minggu dapat dilihat pada Gambar 3 .

Tabel 3. Populasi jantan dan betina kumbang O. rhinoceros yang terperangkap ferotrap selama 1 bulan

\begin{tabular}{ccccc}
\hline \multirow{2}{*}{ Ferotrap } & \multicolumn{3}{c}{ Populasi kumbang } & \multicolumn{2}{c}{ Seks rasio } \\
\cline { 2 - 5 } & Jantan & Betina & Jantan & Betina \\
\hline 1 & 3 & 13 & 1 & 4,3 \\
2 & 3 & 9 & 1 & 3 \\
3 & 3 & 24 & 1 & 8 \\
4 & 4 & 13 & 1 & 3,2 \\
5 & 9 & 38 & 1 & 4,2 \\
\hline Total & 22 & 97 & 5 & 22,7 \\
\hline Rerata & 4,4 & 19,4 & 1 & 4,5 \\
\hline
\end{tabular}




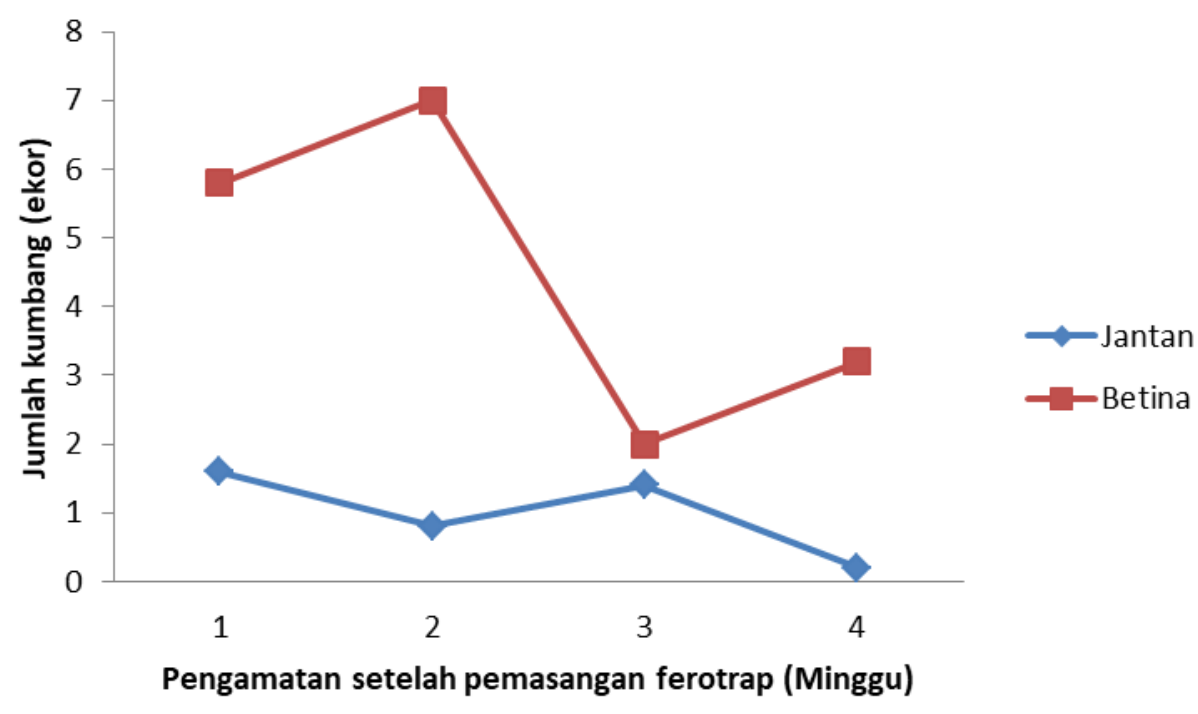

Gambar 3. Fluktuasi kumbang O. rhinoceros pada ferotrap di pertanaman,kumbang betina, b) kumbang jantan.

Berdasarkan Gambar 3 fluktuasi kumbang $O$. rhinoceros betina dan jantan, kumbang $O$. rhinoceros betina tertinggi terdapat pada pengamatan minggu ke2 , sedang kumbang $O$. rhinoceros jantan tertinggi pada minggu ke-3. Hal ini diduga penggunaan ferotrap pada minggu ke-2 sampai ke-3 sudah menyebar terbawa angin dan mulai berkurang pada minggu ke-4. Rahutomo (2008) bahwa senyawa kimia Etil-4 metil oktanoat (feromon agregasi) jika disimpan terlalu lama akan habis menguap.

Menurut Herman (2012) bahwa tingginya jumlah betina dari pada jantan mungkin disebabkan kumbang betina lebih banyak tertarik dengan feromon agregasi dibandingkan yang jantan, karena feromon agregasi dapat menarik jantan dan betina $O$. rhinoceros. Pusat Penelitian Kelapa Sawit (2004), menyatakan bahwa kumbang $O$. rhinoceros yang terperangkap pada perangkap feromon agregasi lebih banyak betina dari pada jantan. Hasil penelitian PPKS (2007) juga menyatakan bahwa dengan penggunaan perangkap feromon lebih banyak $O$. rhinoceros betina yang terperangkap daripada kumbang jantan dengan perbandingan $60-80 \%$ betina dan 20-40\% jantan fluktuasi kumbang jantan.

\section{Intensitas Serangan Kumbang $O$. rhinoceros}

Berdasarkan pengamatan pada tanaman kelapa sawit di PT. Adei Plantation didapat intensitas serangan kumbang $O$. rhinoceros dengan rata-rata sebesar $11,72 \pm 2,01 \%$. Intensitas serangan kumbang O. rhinoceros sebesar $11,72 \%$ tergolong ke dalam kategori serangan ringan. Menurut Kilmaskossu dan Nerokouw (1993) intensitas serangan kumbang $O$. rhinoceros ringan $<40 \%$, intensitas serangan sedang $<60 \%$, dan intensitas serangan berat $>61 \%$.

\section{KESIMPULAN} berikut :

Hasil penelitian dapat disimpulkan sebagai
1. Populasi pradewasa $O$. rhinoceros tergolong rendah yaitu 32 ekor (Total 4 pengamatan dan 27 tanaman sampel) atau 8 ekor perminggu atau 0,29 ekor per tanaman sampel, stadia larva instar 2 lebih dominan ditemukan.

2. Populasi kumbang O. rhinoceros rerata 23,8 ekor per ferotrap.

3. Seks rasio kumbang betina $O$. rhinoceros jauh lebih tinggi dari jantan pada diberi TKKS 19,4 : 4,4 atau $4,54: 1$.

4. Intensitas serangan $O$. rhinoceros sebesar $11,72 \%$ tergolong ke dalam kategori serangan ringan.

\section{DAFTAR PUSTAKA}

Alouw, J.C . 2007. Oryctes rhinoceros (Coleoptera: Scarabaeidae) Pheromone and its Use to Control Coconut Beetle, Oryctes rhinoceros (Coleoptera : Scarabaeidae). Indonesian Coconut and Other Palmae Research Institute.

Chenon, D.C., U. Ginting \& A. Sipayung. 1997. Pengendalian Kumbang Orytes rhinoceros pada Tanaman Kelapa Sawit secara Terpadu. Pertemuan Teknis Kelapa Sawit. Medan.

Chung, G.F. 1997. The Bioefficacy of the Aggregation Pheromone in Mass Trapping of Oryctes rhinoceros (L) in Malaysia. The Planter, 73(852):119-127.

Dinas Perkebunan Provinsi Riau. 2014. Data Kerusakan Kelapa Sawit di Riau. Dinas Perkebunan Kelapa sawit. Pekanbaru.

Dhileepan, K. 1988. Incidence and Intensity of Rhinoceros Beetle Infestation in Oil Palm Plantations in Kerala. Journal of Plantation Corp 16:126-129

Harahap, R. 2010. Kepadatan Jumlah Kumbang Badak (Oryctes rhinoceros L.) pada Tanaman Kelapa Sawit (Elaeis Guineensis Jacq.) di Lapangan. Skripsi. Departemen Ilmu Hama Dan Penyakit Tumbuhan Fakultas Pertanian 
Universitas Sumatera Utara. Medan. (Tidak dipublikasikan).

Herman. 2012. Uji Tingkat Ketinggian Perangkap Feromon untuk Mengendalikan Kumbang Tanduk Oryctes rhinoceros L. (Coleoptera: Scarabaeidae) pada Tanaman Kelapa Sawit. Skripsi. Fakultas Pertanian Universitas Riau. ( Tidak dipublikasikan).

Kilmaskossu STEM \& Nero-kouw J.P. 1993. Inventory of Forest Damage at Faperta Uncen Experi-ment Gardens in Manokwari Irian Jaya Indonesia. Proceedings of the Symphosium on Biotechnological and environmental Approaches to Forest and Disease Management. SEAMEO, Bogor.

Ooi, P.A.C. 1998. Insect in Malaysian Agriculture. Malaysia Tropical Press. Kuala Lumpur

Odum, E.P. 1993. Dasar-dasar Ekologi. Gadjah Mada University Press. Yogyakarta: 137-190.

Pusat Penelitian Kelapa Sawit, 2004. Kumbang Tanduk. http://kliniksawit.com/index.php/hamasawit/ku mbang-tanduk.html. (diakses 12 juni 2016)
Price, P.W. 1984. Insect Ecology. John Wiley \& Sons. New York. USA.

Rahutomo S. 2008. Feromonas Ampuh Basmi Hama Kumbang Sawit. Indonesia, mapiptek. Emegazin, edisi 17 April 2008. Jakarta. Diakses 6 Agustus 2014.

Samsudin, A, P.S. Chew \& M.M. Mohd. 1993. Oryctes rhinoceros Breeding and Damage on Oil Palm to Oil Palm Replanting Situation. the Planter, pp. 68(813) 583-591.

Santi, I.S. dan B. Sumaryo. 2008. Pengaruh Warna Perangkap Feromon terhadap Hasil Tangkapan Imago Oryctes rhinoceros di Perkebunan Kelapa Sawit. Jurnal Perlindungan Tanaman Indonesia. 14(2): 76-79.

Suin, M.N. 2002. Metode Ekologi. Andalas University Press. Padang.

Susanto, A., A.P. Dongoran, Fahridayanti, A.F. Lubis \& A. Prasetyo. 2005. Pengurangan Populasi Larva Oryctes rhinoceros pada Sistem Lubang Tanam Besar. Jurnal Penelitian Kelapa Sawit. 13(1): 1-9.

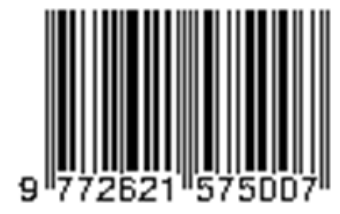

